\title{
ORIENTAÇÃO DE TRABALHOS DE CONCLUSÃO DE CURSO A DISTÂNCIA: UMA EXPERIÊNCIA FUNDAMENTADA NA INTERAÇÃO
}

\author{
Ana Paula Costa e Silva - Universidade Católica de Brasília - asilva@ucb.br \\ Anelise Pereira Sihler - anelisep@ ucb.br \\ Chris Alves da Silva - Universidade Católica de Brasília - chrisalves@ ucb.br
}

\begin{abstract}
RESUMO
Este trabalho visa apresentar as possibilidades de utilização dos ambientes virtuais de aprendizagem e sua importância para a mediação e interação ocorridas entre orientador e orientandos durante o processo de elaboração de trabalhos de conclusão de cursos (TCC) de pós-graduação lato sensu na modalidade a distância. Muitas são as razões que levam um estudante a abandonar um trabalho de conclusão de curso, dentre elas, as dificuldades inerentes a própria produção acadêmica e o sentimento de solidão na etapa final caracterizada pela elaboração individual prevista em legislação. É possível, no entanto, verificar que a interação e a interatividade regulares e eficientes entre orientador e orientandos são condições indispensáveis para a manutenção da motivação, do interesse e da persistência dos que finalizam seu trabalho de conclusão de curso. Neste trabalho, relata-se uma experiência fundamentada na interação por meio do ambiente virtual de aprendizagem Moodle. Constatou-se que os estudantes que interagem com seus respectivos colegas e professores-orientadores, desenvolvendo vínculos afetivos, possuem um grau de satisfação elevado, o que facilita $o$ desenvolvimento do TCC.
\end{abstract}

Palavras-chave: trabalho de conclusão de curso; educação a distância; interação; afetividade.

\section{DEVELOPMENT OF COMPLETION WORK FOR POST- GRADUATION DISTANCE COURSES: AN EXPERIENCE BASED ON INTERACTION}

\begin{abstract}
This paper presents the possibilities of using virtual learning environments and their importance for the mediation and interaction between mentor and mentees during the development of completion work for post-graduation distance courses. There are many reasons why a student leaves a course completion work, among them the difficulties inherent in academic production itself and the feeling of loneliness in the final stage characterized by individual elaboration, provided in legislation. However, it's possible that the regular and efficient interaction between teachers and advisees represents an indispensable condition for the maintenance of motivation, interest and persistence of those who finish their course completion works. In this paper, we report an experience based on interaction through the virtual learning environment Moodle. It was found that students, who interact with their peers and teachers, mentors, developing emotional bonds, have a high degree of satisfaction, which facilitates the development of their final work.
\end{abstract}

Keywords: completion work; distance education; interaction; affectivity. 


\section{INTRODUÇÃO}

O Trabalho de Conclusão de Curso (TCC) representa um importante componente curricular dos cursos de graduação e pós-graduação, sendo comumente estruturado em disciplina obrigatória dos últimos períodos letivos. Muitas são as configurações possíveis dos TCCs, destacando-se dentre elas o artigo científico, a monografia e o projeto de aplicação, que tem como finalidade a articulação da prática com a teoria estudada ao longo do curso. Caracterizado pela produção individual, prevista em legislação, o TCC deve ser reconhecido como um componente privilegiado que visa integrar ensino, pesquisa e extensão.

A produção do TCC é vinculada ao Projeto Pedagógico, integrando ensino, pesquisa e extensão em um espaço institucional que proporciona ao estudante, a partir de conhecimentos já produzidos por autores e por meio da investigação científica, a compreensão do processo de produção acadêmica e de construção de novos conhecimentos, trazendo assim contribuições aos diversos segmentos sociais.

Vivenciando momento de grande expansão, a Educação a Distância $(\mathrm{EaD})$ tem sido cada vez mais procurada por estudantes de graduação e pós-graduação, já que nosso cenário rigorosamente mais competitivo impõe tais exigências para qualquer profissional do século XXI e essa constante atualização ressalta a importância de uma formação coletiva em que se valorize a interação e a aprendizagem cooperativa, contemplando em tal contexto o TCC.

Entende-se, neste trabalho, o estudante como um ser intelectual e afetivo, e a afetividade como sendo inerente ao ser humano. A partir desses dois pressupostos serão discutidos como a utilização do ambiente virtual de aprendizagem Moodle poderá facilitar a construção do TCC, por meio de tecnologias de informação e comunicação (TICs) que privilegiam a interação e cooperação entre professor-orientador e orientandos.

\section{UM NOVO PARADIGMA NA ORIENTAÇÃO DE TCC}

As tecnologias de informação e comunicação disponíveis nos ambientes virtuais de aprendizagem têm possibilitado uma mudança de paradigma no processo de orientação de Trabalhos de Conclusão de Curso. Caracterizado comumente como um processo solitário de pesquisa e produção acadêmica, a elaboração de TCC a distância conquista uma nova dimensão, uma vez que as ferramentas de comunicação disponíveis nos ambientes virtuais possibilitam a interação constante com o professor-orientador, com os demais colegas orientandos, além de facilitar o registro do feedback e das orientações do professor-orientador, bem como de todo processo de construção do trabalho, por meio do histórico das diversas versões construídas e compartilhadas pelo ambiente virtual.

A Resolução $\mathrm{n}^{\mathrm{o}} 1$, de 8 de junho de 2007, estabelece normas para o funcionamento de cursos de pós-graduação lato sensu, em nível de especialização. Os seus artigos $5^{\circ}$ e $6^{\circ}$ tratam especificamente do Trabalho de Conclusão de Curso:

Art. $5^{\circ}$ Os cursos de pós-graduação lato sensu, em nível de especialização, tem duração mínima de 360 (trezentos e sessenta) horas, nestas não computado o tempo de estudo individual ou em grupo, sem assistência docente, e o reservado, obrigatoriamente, para 
elaboração individual de monografia ou trabalho de conclusão de curso.

Art. $6^{\circ}$ os cursos de pós-graduação lato sensu a distância somente poderão ser oferecidos por instituições credenciadas pela União, conforme o disposto no $1^{\circ}$ do art. 80 da Lei ${ }^{\circ} 9.394$, de 20 de dezembro de 1996.

Parágrafo único. Os cursos de pós-graduação lato sensu oferecidos a distância deverão incluir, necessariamente, provas presenciais e defesa individual de monografia ou trabalho de conclusão de curso. (MINISTÉRIO DA EDUCAÇÃO, 2007)

O fato de a legislação exigir e enfatizar que tanto a elaboração quanto a defesa do TCC devem ser individuais não significa que o processo de elaboração não possa ser caracterizado pela interação e pela cooperação entre orientandos na realização de pesquisas, socialização de referências bibliográficas, materiais de estudo, ideias, experiências e contribuições. Afinal, as ferramentas de comunicação e interação atualmente disponíveis contribuem para a construção coletiva de conhecimentos.

\section{A AÇÃO EFETIVA DO ORIENTADOR}

A atuação do professor-orientador, como mediador no processo de elaboração do TCC será essencial para que os estudantes compreendam o significado desta etapa primordial de seu curso. A elaboração do TCC deve ser percebida, por estudantes e professores, como um momento privilegiado de sistematização da aprendizagem, marcado pela realização de pesquisas, organização e registro das ideias e dos conhecimentos construídos ao longo de sua formação.

Dentro de tal perspectiva, torna-se fundamental a mudança de postura do professor orientador, que deixa de ser o reprodutor de conhecimentos e assume o papel de mediador e provocador, trazendo questões que colaborem para uma aprendizagem crítica e reflexiva. Lévy (2003) apresenta a interação trazendo o sentido da necessidade de valorizar-se a construção de conhecimentos de forma colaborativa gerando mudança paradigmática no professor que deixa de ser o detentor único de conhecimentos. $\mathrm{O}$ desenvolvimento de um TCC na modalidade a distância leva a direção da construção para a apropriação do conhecimento que se dá na interação.

Aquele professor que ao longo de muitos anos foi o distribuidor de informações altera sua postura para ser um organizador e orientador da construção do conhecimento do aluno e da sua aprendizagem. Sua importância é potencializada e sua responsabilidade social ampliada. Precisa assumir um "saber humano e não apenas saber informações" (ALVES; NOVA, 2003, p. 19), tendo como foco a qualidade da comunicação ao invés da quantidade de informações transmitidas.

\section{A CONSTRUÇÃO DO TCC AO LONGO DA FORMAÇÃo}

Desde o primeiro período letivo do curso, ao iniciar sua formação, os estudantes devem ter a compreensão de que a elaboração do TCC não se restringe aos últimos períodos letivos, mas perpassa todo o curso. Portanto, o estudante deve ser orientado sobre a importância das atividades e produções que desenvolverá ao longo das disciplinas para a elaboração do seu TCC. Assim, todos os esforços, pesquisas e estudos 
realizados no âmbito de cada disciplina devem convergir para a construção paulatina do TCC durante todo o curso e não somente ao final.

A compreensão da elaboração do TCC como uma etapa final do curso, dissociada da formação nas disciplinas, além de gerar sobrecarga para os estudantes, impede que se estabeleçam processos de reflexão mais aprofundados sobre o tema a ser abordado, sobre o problema da pesquisa, as hipóteses e sobre a fundamentação teórica. Da mesma forma, essa perspectiva impede a realização de pesquisas mais sistematizadas e abrangentes, que possibilitem aos estudantes identificar e conhecer as principais referências bibliográficas relacionadas ao seu tema de pesquisa.

Portanto, parece urgente o desenvolvimento de uma visão diferenciada sobre o processo de elaboração do TCC, como algo que está presente na vida acadêmica do estudante desde a etapa inicial de sua formação, que norteará suas metas de aprendizagem e possibilitará a realização de pesquisas bem mais consistentes, uma vez que nessa perspectiva os estudantes podem ter mais clareza a respeito de onde querem chegar, sobre o que desejam alcançar ao final da formação.

\section{UMA NOVA DIMENSÃO DE ESPAÇO E TEMPO NA ORIENTAÇÃO DE TCC}

Diferentemente da orientação de TCC na modalidade presencial, caracterizada geralmente por encontros semanais de curta duração entre professores e estudantes, a orientação de TCC por meio de ambientes virtuais de aprendizagem ganha uma nova dimensão de espaço e tempo. A flexibilidade proporcionada pela EAD amplia as possibilidades de interação entre orientadores e orientandos. Assim, os encontros semanais passam a ser substituídos por uma conversação constante, que pode ser realizada de forma síncrona ou assíncrona, com a vantagem de ficar registrada no ambiente virtual de aprendizagem.

$\mathrm{O}$ registro do histórico das orientações e das conversas entre orientador e orientandos facilita o processo de construção do TCC. Os estudantes podem realizar consultas posteriores para esclarecer dúvidas, verificar as recomendações do orientador, rever o feedback do orientador e os aspectos do TCC a serem aprimorados. Da mesma forma, os professores podem acessar facilmente, de qualquer lugar e qualquer momento, cada uma das versões do TCC publicadas por cada orientando, revisitar suas observações e recomendações, observar o cumprimento dos prazos definidos para a realização de cada etapa. Tais facilidades facilitam o trabalho do orientador, que pode realizar um acompanhamento constante e sistemático de cada orientando.

Outra vantagem que pode ser associada à orientação de TCC pelo ambiente virtual de aprendizagem é a facilidade de interação com os demais colegas orientandos. O professor pode organizar fóruns de discussões com diferentes objetivos: socialização de referências bibliográficas e materiais de pesquisas; socialização das experiências vivenciadas no decorrer da elaboração do TCC; esclarecimento de dúvidas; orientações individuais.

Diante de tantas mudanças, a inovação e o avanço da EaD tem exigido um novo aprendizado do aluno e também do professor, sendo tais perspectivas levadas para o TCC. Tavares (2006, p. 1) reflete que a aprendizagem cooperativa privilegia o compartilhamento de um objetivo comum, e sua metodologia envolve a interação, que precisa quebrar a lógica do ensino tradicional indo a uma práxis inovadora, permeada pela relação afetiva com o conhecimento e com o orientador, de forma mais autônoma.

Torna-se bastante importante lembrar que esse ambiente virtual precisa trazer o sentimento de pertencimento necessário ao desenvolvimento de um contexto 
cooperativo, além de privilegiar um efetivo conhecimento das pessoas, que resulte em desenvolvimento de afinidades o que atenuará as dificuldades inerentes ao processo de aprendizagem na modalidade a distância e evitará a evasão, fazendo com que o estudante se mantenha motivado.

Como citado por Escovedo (2006), as pessoas sentem-se estimuladas por diferentes motivos e um software de ensino, só alcançará seus objetivos se for capaz de se adaptar a cada estudante e privilegiar um tratamento individualizado, personalizado.

Moran (2003) discute a importância de manter os estudantes motivados, criar boas expectativas, desenvolver a confiança e organizar o processo de aprendizagem, onde os encontros devem ser agradáveis, interessantes, pois isso facilita todo o processo posterior. A motivação, apesar de intrínseca, pode ser estimulada a partir de discussões que tragam exemplos interessantes para o estudante, sejam eles nos chats, fóruns ou atividades colaborativas no ambiente virtual.

Vygotsky, Piaget e Wallon pesquisaram com ênfase a importância da afetividade no processo ensino e aprendizagem. Sabe-se que a afetividade não altera $o$ funcionamento da inteligência, mas poderá interferir no desenvolvimento dos indivíduos trazendo impactos no funcionamento das estruturas da inteligência. É essencial o desenvolvimento do sentimento de comunidade; a interação privilegia e estimula alunos e professores a debater os temas de forma efetiva no ambiente virtual. Incentivar a interação é papel fundamental do professor e provavelmente uma das suas tarefas mais importantes no ambiente de aprendizagem. (PALLOF e PRATT, 2004, p.134)

A utilização de ambientes virtuais de aprendizagem para a orientação de TCC não se restringe à modalidade de educação a distância, pois na educação presencial também é possível tirar proveito de todo o potencial desses ambientes e organizar salas específicas de TCC que viabilizem a interação constante entre os professores e seus orientandos.

Certamente, a orientação de TCC nessa perspectiva exige uma dedicação maior do professor, um tempo maior para a organização e gestão dos espaços de interação do ambiente virtual de aprendizagem, além de uma atenção constante à trajetória percorrida por cada um dos seus orientandos. No entanto, as vantagens e benefícios que representa, tanto para professores quanto para estudantes, superam em muito as dificuldades e exigências de maior dedicação de tempo por parte do professor.

$\mathrm{O}$ ambiente de aprendizagem presencial é um ambiente que existe dentro de quatro paredes, espaços reais construídos com a finalidade educativa. Já os ambientes virtuais de aprendizagem são atemporais, abertos e limitados; não são cercados por espaços físicos, são informações que trafegam e cruzam fronteiras geográficas em tempo real, estimulados visualmente e mentalmente pelos espaços nos quais os estudantes se movem, buscam, codificam, abstraem, com o objetivo de propiciar a interação entre agentes humanos e artificiais. (BELLONI, 2003)

\section{CONTEXTO DA PESQUISA E ANÁLISE DOS DADOS}

Matriculados em cursos de Pós-graduação oferecidos integralmente on line de diferentes áreas de conhecimentos, participaram do estudo 30 alunos que estavam concluindo a disciplina TCC. A população pesquisada foi composta por alunos que finalizavam o curso. $\mathrm{O}$ instrumento aplicado com o objetivo de coletar informações sobre o grau de satisfação dos alunos e os fatores que contribuem para dificuldades e/ou sucesso na disciplina TCC contemplou questões estruturadas e semi-estruturadas sobre: 
desempenho do aluno; relações interpessoais com o professor e com os colegas; apresentação do conteúdo; e principais dificuldades enfrentadas ao longo das disciplinas.

As informações colhidas através de questões, por meio da atribuição de notas de 0 a 10, foram tabuladas de forma direta, com a utilização da estatística e os resultados foram transformados em percentuais.

As questões abertas foram analisadas, classificadas e divididas em categorias, a partir de palavras-chave. Destaca-se abaixo parte dos resultados:

Na questão que solicita a avaliação sobre a importância da discussão nos fóruns para a melhor compreensão do conteúdo, $100 \%$ dos alunos concorda que a participação nos fóruns é um item de grande importância para interagir com professores e colegas e diluir as dúvidas. Tal interação também está diretamente ligada ao bom desempenho do aluno e ao nível de motivação para continuar a disciplina. No item que fala sobre a contribuição da interação para a organização na disciplina novamente, $100 \%$ avaliou com notas entre 9,5 e 10, registrando a importância da interação para que haja o aprendizado.

Algumas frases marcantes trazem que: "As intervenções são fundamentais para o desenvolvimento do trabalho e a presença constante da professora, sempre preocupada e atenciosa, foram fundamentais para o sucesso do meu TCC". Ainda: "O professor, através da interação constante transmite calma e tranquilidade para os estudantes" e "A professora sempre competente e parceira transmite segurança e não permite acomodação".

Outro aspecto muito valorizado, lembrado por todos os alunos, é a interação cooperativa com os colegas, o que contribui efetivamente para resultados positivos.

A pesquisa realizada nos cursos e os dados coletados e analisados permitem considerar a relevância da interação e das discussões nos fóruns, assim como, das relações desenvolvidas entre professor/aluno/grupo durante o processo ensino e aprendizagem do TCC como contribuição para o aumento da satisfação e da motivação do aluno na disciplina.

\section{CONSIDERAÇÕES FINAIS}

O papel do professor orientador é de extrema importância para a manutenção da satisfação do estudante e não pode ser apenas de apoio e sim um atendimento personalizado e permeado pela afetividade; cabe a ele instigar e despertar no aluno o interesse e a curiosidade em prosseguir e ir além do que lhe é oferecido. Podendo ser considerado "âncora do processo" o professor, ao utilizar as ferramentas tecnológicas com foco na interação e mediação de qualidade, não deverá ser apenas referência acadêmica, orientando a aprendizagem dos alunos e tirando suas possíveis dúvidas, mas acima de tudo ser referência como pessoa para cada um de seus alunos.

A pesquisa aqui desenvolvida corrobora com citações de autores como Kort e Reilly (2006) que apontam a importância do desenvolvimento da afetividade no ambiente virtual para trazer de volta estudantes que desaparecem ao longo das orientações, ainda e Santos (2003) que enfatiza o AVA como ferramenta que potencializa a interação.

A experiência de orientação de TCC em ambientes virtuais de aprendizagem abre novas possibilidades em termos de interação, cooperação entre estudantes e produção coletiva de conhecimentos. Assume um significado bem mais abrangente para estudantes, que tem oportunidade de se envolver no processo de elaboração de forma 
mais completa e continuada, como pode ser observado nos resultados da pesquisa devolvendo para a sociedade contribuições relevantes e significativas. Em contrapartida orientar a distância torna-se um processo inovador é possível onde a interação é parte essencial de todo o processo.

\section{REFERÊNCIAS BIBLIOGRÁFICAS}

ALVES, L. e NOVA, C. (org). Educação a Distância: uma nova concepção de aprendizado e interatividade. São Paulo: Futura, 2003.

BELLONI, M. L. Educação a distância. 3. ed. Campinas, SP: Autores Associados, 2003

ESCOVEDO, T. Um framework tutor inteligente para sugestão de exercícios. Proposta de pesquisa para a dissertação de mestrado do Depto. Informática na PUC-Rio, 2006.

KORT, B.; REILLY, R. Theories for Deep Change in Affect-sensitive Cognitive Machines: A Constructivist Model. Disponível em: <http://ifets.ieee.org/periodical/vol_4_2002/kort.html em 02/abril/ 2012.>

LÉVY, P. Educação e Cibercultura. 2003. Disponível em: <http://www.sescsp.org.br>. Acesso em: 25 de abril de 2012.

MASETTO, M. T. Mediação pedagógica e o uso da tecnologia. In: MORAN, José Manuel; MASETTO, Marcos T.; BEHRENS, Marilda Aparecida. Novas tecnologias e mediação pedagógica. Campinas, SP: Papirus, 2001.

MINISTÉRIO DA EDUCAÇÃO. Estabelece Normas para o Funcionamento de Cursos de Pós-graduação Lato Sensu, em nível de Especialização. Resolução n. 1, de 8 de junho de 2007. Disponível em: http://portal.mec.gov.br/cne/arquivos/pdf/rces001_07.pdf.

MORAN. José Manuel. Contribuições para uma pedagogia da educação on line. In: SILVA, Marco (Org.) Educação on line: teorias, práticas, legislação, formação corporativa. São Paulo: Loyola, 2003.

PALLOF, Rena M.; PRATT, Keith. Construindo comunidades de aprendizagem no ciberespaço: Estratégias eficientes para salas de aula on-line. Porto Alegre: Artmed, 2002.

Artmed, 2004.

O aluno virtual: um guia para trabalhar com estudantes on-line. Porto Alegre:

TAVARES, Romero. Aprendizagem significativa em um ambiente multimídia. V Encuentro Internacional sobre Aprendizaje Significativo. Madrid- Espanha, 2006. 